\title{
Effects of High Temperature on Morphological and Physiological Stages of Different Cultivated Crops
}

Muhammad Sajid*, Mehwish Kifayat, M. Salman, M. Usman, Saif-ur-Rahman \& M. Abu Bakar Saddique

Institute of Plant Breeding and Biotechnology, MNS-University of Agriculture, Multan-60000, Pakistan.

Corresponding Author Email: sajidsans@gmail.com*

DOI: http://doi.org/10.46382/MJBAS.2021.5405

Copyright: () 2021 Muhammad Sajid et al. This is an open access article distributed under the terms of the Creative Commons Attribution License, which permits unrestricted use, distribution, and reproduction in any medium, provided the original author and source are credited.

ABSTRACT

Agriculture plays a crucial role in the economic growth of many countries due to its wide share in gross domestic products. Both of the major and minor crops including cotton, wheat, rice maize, sugarcane, millet, sorghum, etc. are being cultivated all over the world. But the cultivation of these crops is directly affected due to the environmental fluctuations. The earth temperature increased rapidly in recent few decays due to the emission of greenhouse gases. About $28 \%$ greenhouse gasses are produced from agricultural sectors. Increment in temperature, impaired all the morphological and physiological activities which are correlated with plant growth and development. It affects the germination rate, plant height, No. of tillers, plant biomass, internodal distance, root, shoot growth. Photosynthesis, respiration rate cell metabolism, fertilization, formation and maturation of fruits. Heat stress for a long period causes many ultrastructural malformations of the cell compartments like the nucleus, endoplasmic reticulum, mitochondria and plastid. To overcome the heat stress plants have adapted many physiological, morphological and biochemical strategies. In physiological strategy, plants adapted heat avoiding, tolerance and resistance phenomenon. In biochemical strategy, plants activate such enzymes which reduce the effects of heat stress. Both physiological and morphological strategies fruitful for plants to survive under heat stress conditions.

Keywords: Adaptations, Greenhouse gasses, Heat stress, Nutrients role, Oxidative damage.

\section{Introduction}

The earth's temperature increased with time due to the continuous emissions of greenhouse gases. The emission of greenhouse gases, agriculture is the major source that contributes about $28 \%$ in total greenhouse gas production in the form of rice cultivation and fermentation process in farmyard manures, which emit methane, carbon dioxide and nitrous oxides gases, respectively. An increment in temperature causes numerous morphological and physiological changes in many plants such as the reduction in seed germination percentage, high transpiration rate, reduction in respiration, reduction in photosynthesis, pollen viability and production of reactive oxygen species in many plant species. Due to the heat stress growth period of plants also reduced. About $30 \%$ yield of cereal and oilseed crops lost due to climate change. In cereals, a very minute change in temperature i.e. $1-2{ }^{\circ} \mathrm{C}$ from the ideal range disturbs the grain filling stage which ultimately harms crop production. High temperature also changes the appearance of many genes that are involved to protect the cell from injury under high temperature. Such genes are liable for the activation of osmoprotectants, enzyme detoxification and many other proteins regulation [1],[2].

Under high temperature the morphological and biochemical methods are modified by the expression of these genes. There are many ways to overcome heat stress and it is noted that plants respond the heat stress by adapting the morphological changes. Morphological adaptions included rolling of leaves and twigs, shedding of leaves, changing in the leaf angle and closure of stomata. On the other hand, plants also show the molecular response against heat stress. At the molecular level heat shock proteins play a crucial role to overcome heat stress.

These proteins are also called molecular chaperons. The HSPs are expressed under heat stress conditions and protect the plant cell from injury. Some major effects of heat on crops are summarized below [3]. 


\section{Impacts of Thermal Stress on Plants}

Plants can respond to high temperature but it depends upon the plant species duration of stress, plant growth stage and intensity of the stress. Under extreme conditions plant, cell injury or cell death occurs within a few minutes, which may prompt a calamitous breakdown of cell association. Most probably, all the growth stages of the plants are affected by high temperature such as germination, seedling growth, reproductive growth and yield.

High temperature also affects the protein stability, membrane composition, RNA and its structure and reducing the ability of enzymes through which the cellular metabolism un-stabilized [4].

\section{Morphological Stages}

\subsection{Plant growth}

Among the growing steps of the plant, the initial stages are badly affected by the high temperature firstly, thermal stress harms various plant growths especially at seed germination. Various effects of thermal stress on plant growth including a reduction in germination, poor plant emergence, poor seedling and seedling vigor, reduction in the growth of plomule and radicle [5]. Under heat stress, seed germination is inhibited due to the induction of abscisic acid. At high $\left(45^{\circ} \mathrm{C}\right)$ temperature the germination of the wheat crop is impaired, embryo for seedling initiation rate is also decreased and ultimately cell death.

High temperature alters the plant growth period even increase $1-2{ }^{\circ} \mathrm{C}$ from ideal temperature decrease the grain filling duration and ultimately reduction in yield in cereal crops. In cereal crops, major parameters are impaired due to heat stress such as germination interval, anthesis stage and ripeness which is a major source of reducing yield [6]. Due to the denaturation or amassing of proteins under heat stress condition causes programmed cell death through which plant shed its leaves, flower abortion and fruit or even complete plant death.

\subsection{Reproductive stage}

As, heat stress effect all the stages of the plant growth and its development but among these stages reproductive stage highly sensitive to thermal stress, even a single degree up or down from the ideal temperature at the flowering stage cause serious loss of grain yield in cereals. At the reproduction stage, floral buds and pollen abortion are common in plants but sometimes plants lose their ability to produce flowers or fruit/seed may not be produced under heat stress conditions.

The major reason for sterility under heat stress condition is improper meiosis mechanism in male as well as female organs and as a result, poor pollen germination, poor viability of ovule, growth of pollen tube reduce, reduction in pollen grains number, improper fertilization, structural changes of endosperm and poor fertilized embryo [7].

At the heading stage, temperature greatly affects anthers dehiscence and pollen viability and reduces the number of pollen on stigma which is the main reason for sterile spikelets in rice. Ethylene is produced in rice plants under heat stress which prohibits the activity of the starch and sugar metabolism enzymes which ultimately cause poor grain filling and develop sterile grains. High thermal stress alters silking and grain filling periods in maize crops, while on the other side high temperature decrease the seed number and viability of pollens in soybean crop [8]. 


\subsection{Poor pollen development and viability}

The initial developmental stages of pollen are significantly affected by temperature. The more critical stages in the tomato plant 7 to 15 days ahead of anthesis and mainly at the meiosis stage. Although, thermal effects didn't influence the quality of pollen segments or at meiosis period once heat increased than the ideal level after the reveal of a quartet. In peanut plants, anthesis and microspore formation stages are more susceptible to heat stress. Under heat stress, the microspore mother cell leads to reduce the viability of pollen but at lateral stages, temperature does not affect the pollen viability in bell paper [9].

Under thermal stress, pollens are unfavorably influenced because pollens are known as the most sensitive parts of the plant. In many plants, the quantity of fruits is diminished in response to the sterility of pollens because of thermal pressure. In this way, crop production relies on heat throughout pollen formation. Temperature range (18 to $25{ }^{\circ} \mathrm{C}$ ) is viewed as suitable for superior tomato production but the increment in temp. " $>25{ }^{\circ} \mathrm{C}$ " prompts a decrease in production. The unfriendly impacts of thermal strain on the viability of pollens are accounted for in many crops for example grain, common bean, bell pepper, rapeseed, strawberry, tomato, rice, chickpea and soybean. In many crops, it is noted that thermal stress at the time of flowering is the main reason for the reduction of yield of the crops [9],[10].

In various plant species although the variation is present related to thermal stress the reproductive stage is very critical in response to temperature. A minute change in temperature automatically affects the buds and causes the abortion of flowers. Thermal stress directly affects the viability of pollens, its germination, and length of the pollen tube, ovule viability, disturbing the location of style and stigma and impaired the fertilization process which is the main reason for the reduction in production in many crops species. Many studied shoes that increment in heat stress, cause a severe reduction in pollen formation, its viability and poor fertilization mechanism. Like other plants, thermal tolerance varieties of rice show minute effect heat stress that thermal susceptible [10].

\subsection{Yield loss}

A negative association between plant phenology and high temperature reduces the yield of various crops mostly grain of cereals and oilseed crops. It is reported that increment in day and night temperature causes negative effects on the yield of any crop. Even a single degree change in optimum temperature cause 4.1-10.0\% yield loss in cereal crops. Heat susceptible crop varieties are significantly affected by high temperature as compared to the tolerant varieties, thousand grain weight in cereal crops also reduces upto $7.9 \%$ under high temperature [10].

In rice crop, nigh temperature also reduces the length, width and weight of grain by $2 \%$ and enhances the sterility upto $61 \%$. Under heat stress condition nitrogen concentration increases in grain which is negatively associated with the grain weight and causes $90 \%$ yield loss. In wheat crop dough and maturity, stages are also affected by the high temperature which causes the small and low weight of kernel which ultimately a source of yield loss. Moreover, in cotton, the yield is adversely affected due to the disturbance of the photosynthesis rate and respiration rate of the plant mainly impaired because of increment in temperature [11]. An increment in thermal pressure also affects the crop yield and quality. In barley, the grain characteristics disturb in such sense the concentration of 
maltose and proteinogenic amino acid contents enhanced, while on other hand the non- fundamental carbohydrates, starch, raffinose, fructose, aluminum and lipids decline. The pod superiority also disturbs in the form of fiber contents and degradation of Ca pectate in okra under high temperature [12].

\section{Physiological Stages}

\subsection{Photosynthesis}

In physiological mechanisms of plants, photosynthesis is one of the major heat susceptible phenomenon, especially in $\mathrm{C}_{4}$ and $\mathrm{C}_{3}$ plants. Most changes occur in the cell's chloroplast, which is also known as the initial site of injury due to the photochemical reactions in thylakoids organelle.

In chloroplast, heat stress changes the structure of thylakoids, swelling, stacking and loss of grana. Thermal stress also disturbs the mechanism of the photosystem II due to the reduction in photosynthetic required dyes. Plants maintain the balance of gaseous exchange of leaf and rate of assimilation of $\mathrm{CO}_{2}$ which are directly linked to thermal tolerance. Thermal stress significantly impaired water potential in leaf, stomatal conductance and concentration of carbon dioxide within the cell [11].

Under stress, condition plants close their stomata to reduce the transpiration rate which is also a major reason for the reduction in photosynthetic rate. In the sorghum crop, chlorophyll pigments reduce due to the result of thylakoid and chloroplast lipid peroxidation under thermal condition. In soybean crop, high temperature decrease the chlorophyll content, sucrose content and sugar content $18 \%, 9 \%$ and $47 \%$, respectively. It is considered that reduction insoluble proteins, Rubisco binding proteins large and small subunits of the Rubisco in night and increment in the day are also the main reasons to impair the photosynthetic rate in crops.

Some major photosynthetic enzymes efficiency also affected due to high temperature such as "sucrose phosphate synthase, ADP glucose pyro-phosphorylase and invertase" through which synthesized starch as a result ultimately sucrose decreased [11],[12].

\subsection{Reactive oxygen species}

Inter and intracellular biochemical mechanism are controlled by the activation of proper responsible enzymes, but under thermal conditions, the efficiency of these enzymes significantly affected which provide the major space for the production of reactive oxygen species (ROS). These ROS are mostly originated from chloroplast (chemical reaction of PS-I and PS-II), peroxisomes and mitochondria. Under heat stress conditions the absorption mechanism of photon altered which resulted the production of ROS effect. ROS includes ${ }^{1} \mathrm{O}_{2}, \mathrm{O}_{2}{ }^{\bullet-}, \mathrm{H}_{2} \mathrm{O}_{2}$ and $\mathrm{OH}$.

The most producing ROS is $\mathrm{O}_{2}^{\bullet-}$ which is originated by the chemical reaction in flavor-proteins, redox cycling Mahler reaction of chloroplast, electron transport chain mechanism in mitochondria, oxidation of NADPH in the plasma membrane of the cell, oxidation of xanthine and polypeptides chain of the membrane are the major source $\mathrm{O}_{2}^{\bullet-}$ production. The $\mathrm{H}_{2} \mathrm{O}_{2}$ produces when it reacts with $\mathrm{O}_{2}^{\bullet-}$ or with $\mathrm{Fe}^{2+}$ and by the decomposition of $\mathrm{O}_{3}$. The $1 \mathrm{O}_{2}$ produce by the inhibition of photons and PS II mechanism of electron transfer in the chloroplast [12]-[14]. The effects of ROS are summarized in the Table 1 and the mechanism of cell death due to ROS is described in Figure 1. 
Table 1. Effects of ROS on different crops

\begin{tabular}{|c|c|c|}
\hline Crops & Effects & References \\
\hline Gossypium hirsutum & $\begin{array}{c}\text { Membrane injury, lipid peroxidation of } \\
\text { the membrane, protein proteolysis into a } \\
\text { soluble form and cause pre-mature } \\
\text { leaves senescence }\end{array}$ & [12] \\
\hline Oryza sativa & $\begin{array}{c}\text { MDA concentration increased in leave } \\
\text { and reduction of antioxidant enzymes }\end{array}$ & [12] \\
\hline Glycine max & $\begin{array}{c}\text { Membrane injury and lipid peroxidation } \\
\text { of membrane }\end{array}$ & [12] \\
\hline Sorghum bicolor & $\begin{array}{r}\text { Membrane injury, lipid peroxidation of } \\
\text { the membrane and Increase the } \\
\text { membrane rupturing and MDA } \\
\text { concentration }\end{array}$ & \\
\hline
\end{tabular}

The hydroxyl radicals react with the plant cell components like pigments, DNA, lipids, and proteins. Heat stress also a source of oxidative stress which significantly affects the cell membrane lipid peroxidation, altered the stability of cell membrane and denaturation of proteins. Thylakoid membrane ruptured and electrons are released which is the main source for the production of ROS even under moderate heat stress [14].

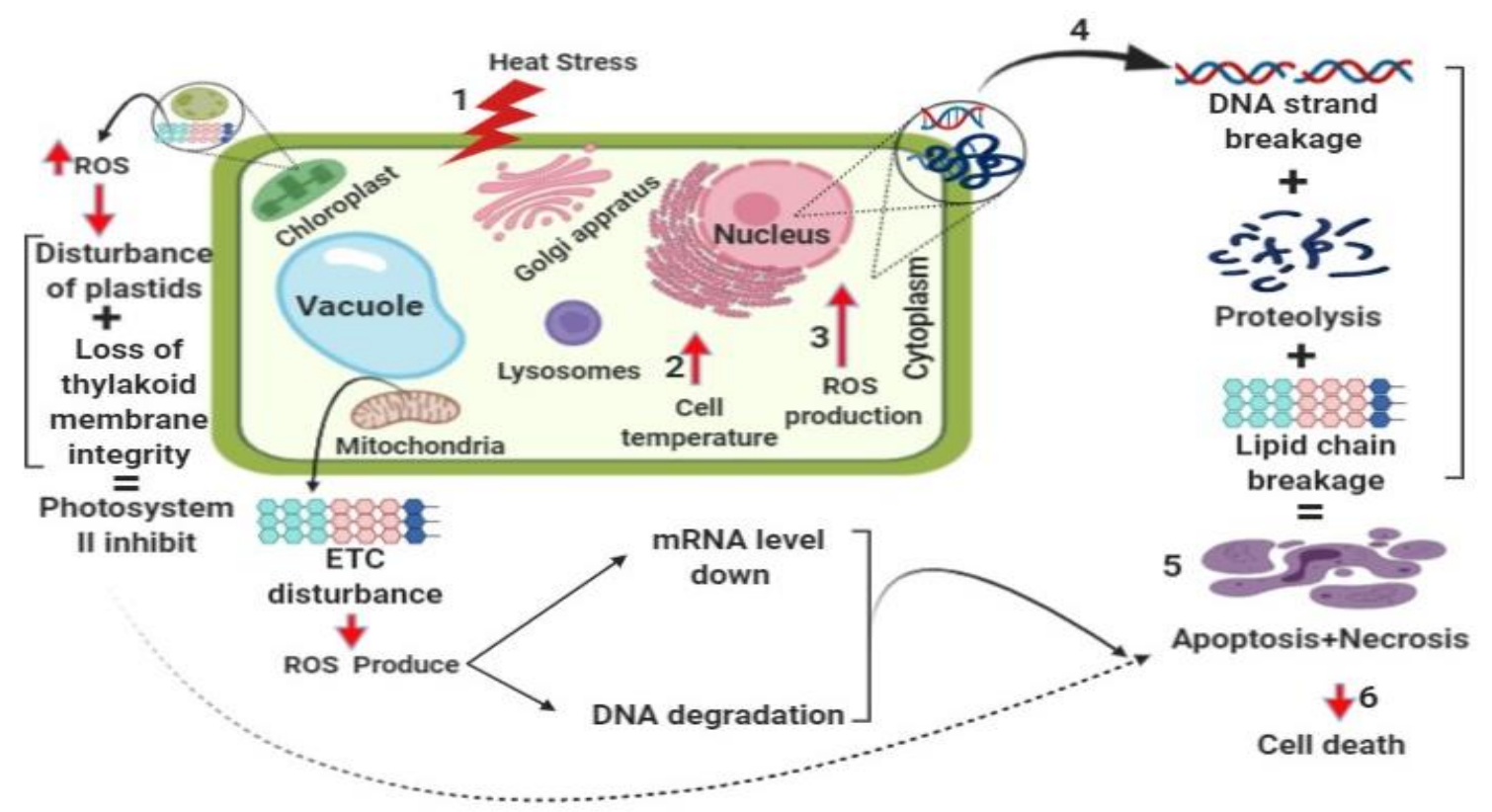

Fig.1. Plant cell death mechanism under ROS stress

\subsection{Nutrient uptake phenomenon}

Plant's roots and shoots are sensitive to heat stress, which significantly affects their growth vigor. Under heat stress conditions the root growth, number, mass and above ground tissues growth reduced due to the restriction of water 
and nutrients supply. Both macro (NPK) and micronutrients i.e. ( $\mathrm{Br}, \mathrm{Mn}, \mathrm{Mg}$ and $\mathrm{Fe}$ ) are essential for proper plant growth and development but the sink-source relationship is disturbed because of heat stress. It reduced the amount of hormones and their transportation mechanism from root to shoot.

It is studied that heat stress affects the production of the nutrient in leaf tissues even reduces the total nutrient concentration in plant parts [15],[16]. Nutrient uptake phenomenon is also affected due to the lower production of such enzymes which are essential for nutrients metabolism i.e. nitrate and ammonium assimilation [17].

Heat stress decreases the root mass, root area and nutrient uptake per unit root. Due to the depletion of total non-structural carbohydrates nutrient uptake per unit root decreased which also affects the function or production of nutrient uptake proteins i.e. nitrate reductase and glutamine synthetase [17].

\section{Conclusion}

All the morphological and physiological stages of many crops, vegetables and fruits badly effected due to high temperature. Heat stress reduces the germination, growth stages, nutrient uptake phenomenon and yield. It is also a source of ROS production that directly or indirectly effects the cell internal and external environment. To keep in mind the effects and reasons of heat stress, there is a need to develop the heat resistance crops that have the ability to survive under high stress conditions and gave high and quality yield.

\section{Declarations}

\section{Source of Funding}

This research did not receive any grant from funding agencies in the public, commercial, or not-for-profit sectors.

\section{Competing Interests Statement}

The authors declare no competing financial, professional and personal interests.

\section{Consent for publication}

Authors declare that they consented for the publication of this research work.

\section{Availability of data and material}

Authors are willing to share data and material according to the relevant needs.

\section{References}

[1] Krasensky J and Jonak C. Drought, salt, and temperature stress-induced metabolic rearrangements and regulatory networks. J. Exp. Bot., 2012; 63(4): 1593-1608.

[2] Semenov MA and Halford NG. Identifying target traits and molecular mechanisms for wheat breeding under a changing climate. J. Exp. Bot., 2009; 60(10): 2791-2804.

[3] Moreno AA and Orellana A. The physiological role of the unfolded protein response in plants. Biol. Res., 2011; 44(1): 75-80. 
[4] Suzuki N, Koussevitzky S, Mittler R and Miller G. ROS and redox signalling in the response of plants to abiotic stress. Plant Cell Environ., 2012; 35(2): 259-270.

[5] Cheng L, Zou Y, Ding S, Zhang J, Yu X, Cao J. et al. Polyamine accumulation in transgenic tomato enhances the tolerance to high temperature stress. J. Integr. Plant Biol., 2009; 51(5): 489-499.

[6] Wahid A, Gelani S, Ashraf M and Foolad MR. Heat tolerance in plants: an overview. Environ. Exp. Bot., 2007; 61(3): 199-223.

[7] Maheswari M, Yadav S, Shanker AK, Kumar MA, Venkateswarlu B. Overview of plant stresses: Mechanisms, adaptations and research pursuit. Crop stress and its management: Perspectives and strategies: 2012; 1-18.

[8] Tan W, wei Meng Q, Brestic M, Olsovska K and Yang X. Photosynthesis is improved by exogenous calcium in heat-stressed tobacco plants. J. Plant Physiol., 2011; 168(17): 2063-2071.

[9] Sakata T, Takahashi H, Nishiyama I and Higashitani A. Effects of high temperature on the development of pollen mother cells and microspores in barley Hordeum vulgare L. J. Plant Res., 2000; 113(4): 395.

[10] Oosterhuis D. Day or night high temperatures: A major cause of yield variability. Cotton Grower, 2002; 46(9): 8-9.

[11] Polley HW. Implications of atmospheric and climatic change for crop yield and water use efficiency. Crop Sci., 2002; 42(1):131-140.

[12] Sumesh K, Sharma-Natu P and Ghildiyal M. Starch synthase activity and heat shock protein in relation to thermal tolerance of developing wheat grains. Biol. Plantarum, 2008; 52(4): 749-753.

[13] Karuppanapandian T, Moon JC, Kim C, Manoharan K, and Kim W. Reactive oxygen species in plants: their generation, signal transduction, and scavenging mechanisms. Aus. J. Crop Sci., 2011; 5(6): 709.

[14] Huang B, and Xu C. Identification and characterization of proteins associated with plant tolerance to heat stress. J. Integr. Plant Biol., 2008; 50(10): 1230-1237.

[15] Bassirirad H. Kinetics of nutrient uptake by roots: responses to global change. New Phytol., 2000; 147(1): 155-169.

[16] Nussaume L, Kanno S, Javot H, Marin E, Nakanishi TM, and Thibaud MC. Phosphate import in plants: focus on the PHT1 transporters. Front. Plant Sci., 2011; 283.

[17] Hungria $\mathrm{M}$ and Kaschuk G. Regulation of $\mathrm{N}_{2}$ fixation and $\mathrm{NO}_{3}-/ \mathrm{NH}_{4}+$ assimilation in nodulated and N-fertilized Phaseolus vulgaris L. exposed to high temperature stress. Environ. Exp. Bot., 2014; 9832-39. 